\section{Eugenia Houvenaghel}

Estudió en la UA (Amberes, Bélgica), en la UAH (Alcalá de Henares) y en la Universidade Católica Portuguesa (Lisboa). Obtuvo su doctorado en literatura hispanoamericana en la UGent (Gante, Bélgica) especializándose en el ensayo mexicano con una beca del FWO-Vlaanderen. Se le concedió una beca de investigación postdoctoral del FWO-Vlaanderen y enseñó las literaturas hispánicas en el departamento de lenguas románicas en la Universidad Radboud de Nimega (Países Bajos). Actualmente es profesora de investigación (BOF, Fondo especial de Investigaciones) de literaturas hispánicas en el departamento de español de la UGent (Gante, Bélgica). Ha publicado artículos en diversas revistas literarias sobre relaciones literarias entre Europa y América. Ha dirigido un proyecto de investigación sobre las relaciones entre la herencia clásica grecolatina y la literatura hispanoamericana. Su más reciente proyecto de investigación examina la relación Europa/América en la producción ensayística de la segunda generación del exilio republicano en México.

«Entre Europa y América: Vidas entre dos mundos descritas po Alfonso Reyes», Confluencia, 22, 2-14, 2007; «El eterno retorno de la femme fatale en Circe de Julio Cortázar», Bulletin of Hispanic Studies, vol. 85, 6, 853-856, 2008; «El camino de la reescritura. La metamorfosis en El Divino Narciso de Sor Juana», Anales de Literatura Hispanoamericana, 2010, vol. 38, 289-305; «El pachuco de Octavio Paz (1950): una doble relectura en clave argumentativa y existencialista», Revista de Literatura Hispanoamericana, 2012, «El filósofo mexicano Samuel Ramos: Entre el positivismo europeo y la busca de autenticidad», Confluencia, vol. 29,2014

La construcción del enunciador en una dinámica de debate: Historia Antigua de México (1780-81) de Francisco Clavijero

\section{LA CONSTRUCCIÓN DEL ENUNCIADOR EN UNA DINÁMICA DE DEBATE: HISTORIA ANTIGUA DE MÉXICO (1780-81) DE FRANCISCO CLAVIJERO}

\author{
EUGENIA HOUVENAGHEL \\ Universidad de Gante \\ Eugenia.houvenaghel@ugent.be
}

\section{RESUMEN}

Partiendo del marco de debate que opone Europa y América en el siglo XVIII, nos proponemos estudiar qué relación existe entre dicha polémica y la construcción del enunciador en la Historia Antigua de México (1780-81) de Francisco Javier Clavijero. Para ello, nos apoyamos metodológicamente en la «escenografía», concepto propuesto por Maingueneau para analizar la dinámica enunciativa del discurso que se compone de cuatro categorías interactivas e indisociables: enunciador, co-enunciador, tiempo y espacio. Completaremos el aparato metodológico por medio de la propuesta de Verón y García Negroni sobre la categoría múltiple del co-enunciador en el discurso adversativo. El análisis de tres secciones de la Historia Antigua de México que difieren en cuanto a tonalidad y propósito discursivo nos proporcionan pistas para examinar y comparar los modos en que se pone en escena la dinámica del debate y al mismo tiempo se construye discursivamente la identidad del enunciador. Concluimos que la imagen creada de la instancia enunciadora contradice el espíritu de confrontación Europa/América que caracteriza la «Disputa del Nuevo Mundo».

Palabras clave: Clavijero, enunciador, escenografía, Disputa del Nuevo Mundo, Historia Antigua de México.

\section{ABSTRACT}

As of the debate context that opposes Europe and America in the Eighteenth Century, we will study the relationship between this controversy and the construction of the sender in the Historia Antigua de México (1780-81) by Francisco Javier Clavijero. We base on the concept of «escenografía», proposed by Maingueneau to analyze the dynamics of the speech enunciation. Its consist of four interactive and inseparable categories: sender, co-sender, time and space. We will complete the methodology through the proposal of Veron and Garcia Negroni about multiple category of the co-sender in the adversative discourse. Analysis of three sections of the Historia Antigua de México that differ in tone and purpose discursive provide clues to examine and compare the parts of the debate. At the same time the identity of the sender is discursively constructed. At last, the image of the sender contradicts the spirit of confrontation Europe / America that characterizes the «Dispute of the New World».

Keywords: Clavijero, sender, escenografía, Dispute of the New World, Ancient History of Mexico. 


\section{Introducción}

El naturalista francés George Louis Leclerc, Conde de Buffon, destacado escritor del Siglo de las Luces, propuso en su Historia natural (1749-1789) que en América prevalecía un estado de evolución retardada -tanto para los indígenas como para los animales y las plantas-. El antropólogo holandés Cornelius De Pauw publicó (1768-69) sus Investigaciones filosóficas sobre los americanos en las que planteó, de manera categórica, la inferiordad y la degeneración de los pueblos americanos y de la naturaleza americana en comparación con los del Antiguo Mundo. Otro intelectual europeo de gran prestigio, el abate Raynal escogió en su Historia natural y política de los establecimientos y del comercio de los europeos en las dos Indias (1770) el mismo punto de vista despreciativo sobre el Nuevo Mundo. El historiador William Robertson, a su vez, (Historia de América, 1777) se encargó de repensar la historia de América de acuerdo con las proposiciones del Conde de Buffon y De Pauw. Los criollos reaccionaron contra estas teorías eurocéntricas que no valorizaban la alteridad de América y así se inició la discusión llamada, según el término de Antonello Gerbi (1982), «Disputa del Nuevo Mundo» ${ }^{1}$ que, en las últimas décadas del siglo XVIII enfrentó ilustrados europeos y criollos.

Redactada por el jesuita criollo Francisco Javier Clavijero (Veracruz 1731- Bolonia 1787) para defender el Nuevo Mundo contra las teorías de degradación lanzadas por los naturalistas europeos ${ }^{2}$, la Historia Antigua de México se inscribe en la línea de la disputa dieciochesca en torno a América. En este trabajo, nos preguntamos cómo se plasma la identidad cultural del enunciador en dicha obra. Para ello, proponemos una lectura de la Historia Antigua de México orientada hacia la puesta en escena del debate en torno a América -entre los europeos que «condenan a todo un continente» (Villoro, p. 1950, p. 95) y los criollos que defienden su mundo- en el propio discurso. Esta escena enunciativa de la controversia -en la que se mueven una serie de personajes que dialogan e interactúan- se caracteriza por sus propias tensiones y nos ofrece una perspectiva dinámica sobre el modo en que en ese discurso se configura la identidad del enunciador.

Nos apoyaremos metodológicamente en el concepto de «escenografía», introducido por Maingueneau para referirse a una sección específica de la triple «escena de enunciación» del discurso (Charaudeau/Maingueneau 2005, p. 221). Todo discurso se configura como una escena (Maingueneau 1987, 1999) en la que la distribución de roles entre diferentes participantes y voces juega un papel central. El elemento "grafía» debe interpretarse a la vez como «marco» y «proceso» (Maingueneau/Angermüller, 2007, p. 222): así pues, la escenografía es a la vez la escena de la que procede el discurso y la escena que produce el discurso. Maingueneau (1993, p. 123) propone cuatro categorías que interactúan entre ellas y a partir de las cuales pretende desarrollarse la enunciación: el «enunciador», el «coenunciador», el espacio y el tiempo.

La dimensión del co-enunciador se complica particularmente en la Historia Antigua de México, lo que se puede explicar a partir del contexto de debate en el que nace y se desarrolla su discurso. El campo discursivo de la Historia Antigua de México implica una dimensión polémica -caracterizada por elementos como «enfrentamiento, relación con un enemigo, lucha entre enunciadores» (Verón, 1987)- a la que nos aproximaremos partiendo de la teoría del discurso adversativo. En este tipo de discursos, explica Verón, «la enunciación parece inseparable de la construcción de un adversario» (1987, p. 16). Sin embargo, el adversario no es el único co-enunciador con el que el enunciador establece un diálogo; uno de los rasgos específicos del discurso utilizado en el contexto del debate es su destinatario múltiple. En efecto, este tipo de discurso suele estar dirigido a tres tipos de destinatarios (García Negroni, 1988, Verón, 1987): un destinatario positivo o prodestinatario (el partidario o adherente que conforma, junto con el enunciador, un «colectivo de identificación» con creencias compartidas), un paradestinatario (el destinatario indeciso) al cual es necesario persuadir; y un contradestinatario o adversario, con el cual se polemiza y al cual se intenta destruir discursivamente. Cuando aplicamos este esquema al texto que nos ocu$\mathrm{pa}$, el contradestinatario correspondería a los ilustrados europeos, cuyo discurso negativo sobre la naturaleza y las gentes de América es rebatido en el texto que nos ocupa; el paradestinatario correspondería a los lectores que vacilan en creer las teorías sobre la inferioridad del Nuevo Mundo y que pueden

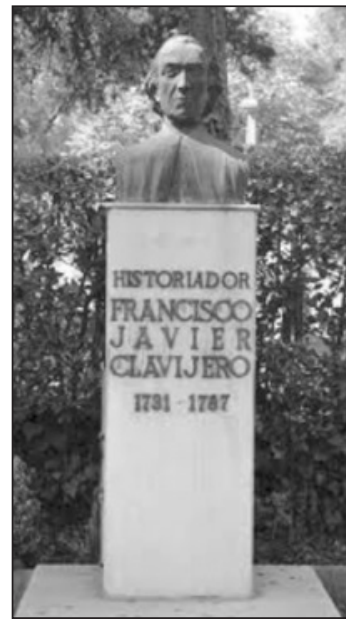

Busto a Francisco Javier Clavijero

1

Un estudio clásico sobre este debate de la llustración fue publicado por Antonello Gerbi en 1955. Más recientemente, David Brading (1991), Jorge CanizaresEsguerra (2001) y Kohut (2008) reconsideraron la cuestión del debate dieciochesco.

En el prólogo (p. XXI), el enunciador formula esta intención como sigue: "restituir a su esplendor la verdad ofuscada por una turba increíble de escritores americanos». Otros objetivos de la obra son: "evitar la fastidiosa y reprensible ociosidad» (los jesvitas expulsos en 1767 en Italia ya no podían ejercer su profesión) y "servir del mejor modo posible» a la patria.

\footnotetext{
La construcción del enunciador en una dinámica de debate: Historia Antigua de México (1780-81) de Francisco Clavijero

EUGENIA HOUVENAGHEL
} 


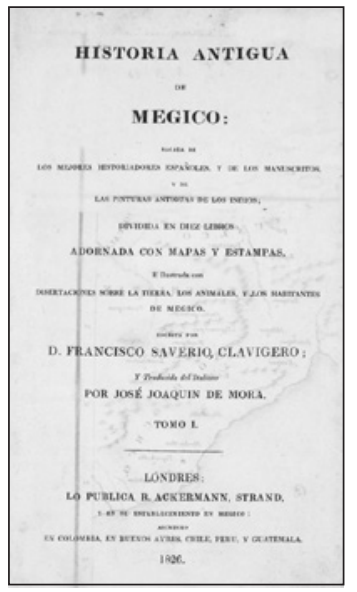

Nacido en la Nueva España en 1731, Claviiero tuvo desde la infancia la oportunidad de entrar en contacto directo con la riqueza lingüistica, biológica y cultural de la tierra de la Nueva España. En 1748 ingresó en la Compañía de Jesús y eligió la filosofía, las letras y la enseñanza de aquellas disciplinas como ocupaciones principales. En 1767 abandonó la Nueva España, tras la orden de expulsión de los jesuitas decretada por el rey Carlos III y fue mandado a Ferrara (Italia) por sus superiores. El exilio llevó consigo para este grupo de jesuitas un alejamiento y una gran añoranza de la tierra natal. En 1773, cuando se declaró suprimida la orden jesuítica, los exiliados se vieron sometidos, además, al ocio. En la década (1770 -1780) en la que redactó su Historia Antigua de México, se encontró en Bolonia, ciudad de grandes archivos y bibliotecas. Clavijero convivió en Bolonia con otros jesuitas expulsados: el poeta Diego José Abad y los humanistas Manual Iturriaga, Rafael Landívar, José Mariano Vallarta. Para más información biográfica acerca de Clavijero, véase Ronan (1977).

La construcción del enunciador en una dinámica de debate: Historia Antigua de México (1780-81) de Francisco Clavijero

EUGENIA HOUVENAGHEL ser persuadidos de la tesis contraria; el prodestinatario, finalmente, correspondería a los lectores ya convencidos del valor de la civilización prehispánica. La función del discurso es diferente para cada tipo de destinatario (Verón, 1987, p. 17): es de «refuerzo» frente al prodestinatario, de "persuasión» frente al paradestinatario y de «polémica» frente al contradestinatario. Nos preguntaremos, en este análisis, qué presencia y significado adquiere cada uno de estos tipos de destinatarios en la puesta en escena del texto y cómo se interrelaciona con el enunciador.

La dimensión espacial es otra categoría que se complica particularmente en el discurso de Clavijero. Este hecho no ha de sorprendernos: la polémica se inscribe en una fuerte tensión de ataque y defensa entre el espacio europeo y americano. A esta situación espacial caracterizada por relaciones conflictivas entre dos mundos, se suma el exilio en el que se encuentra el grupo de jesuitas al que pertenece Clavijero 3 . Nordenflycht (2010), en este contexto, ha analizado la producción de los jesuitos americanos expulsos a la luz de la noción de «paratopía» (Maingueneau, 1993, 26 y ss.), o «no-lugar» del exilio. Nordenflycht desarrolla en su estudio algunos aspectos paratópicos de la escritura de los jesuitas americanos expulsos: destaca su situación en un no-lugar entre dos espacios, ya que los desterrados se encuentran entre Europa y América, entre el centro del objeto que describen y el margen de este mismo, entre el mundo dominado por el pensamiento ilustrado y el mundo de la tradición prehispánica. En nuestro estudio, el espacio se analiza sobre todo en función de la dinámica del debate que se establece entre enunciadores y destinatarios de diferentes continentes.

Estructuralmente la Historia Antigua de México se compone de un aparato paratextual, seguido por el cuerpo del texto (que va dividido en diez unidades) y un conjunto de «Disertaciones». El espacio limitado de esta contribución no nos permite analizar en detalle la dinámica enunciativa de cada parte de la Historia Antigua de México. Estudiamos, en primera instancia, un componente que ocupa un lugar clave en el desarrollo de la idea de controversia: las «Disertaciones» (Clavijero, 1971, pp. 424-592), dedicadas a refutar las teorías acerca de la inferioridad de América. En segundo lugar, hemos incluido en el corpus un apartado del texto dedicado a la temática central de la polémica, a saber, el primer libro (Clavijero, 1972, pp. 1-47) de la Historia Antigua de México, que versa sobre la naturaleza del territorio novohispano. El contraste entre ambos apartados del corpus, el primero de índole descriptiva y el segundo de índole argumentativa, agrega una plusvalía al corpus y ofrece perspectivas para comparar las modalidades de construcción del enunciador. Finalmente, es imprescindible explorar en este estudio el paratexto (Clavijero, 1971, pp. I-XXXVII y pp. 422-23), ya que es un lugar privilegiado de la escenografía y proporciona elementos imprescindibles acerca de la configuración del enunciador y co-enunciador. En estos apartados preparatorios, el enunciador anuncia su intención respecto al tema y establece, así, un contrato comunicativo con el lector. Los componentes del aparato paratextual completan, por lo tanto, el corpus de este estudio.

\section{Análisis}

\subsection{En el umbral del texto}

Tres elementos paratextuales o escritos anticipatorios preceden el cuerpo del texto: una carta dedicatoria ( A la Real y Pontificia Universidad de México», pp. XVII-XIX), un «prólogo del autor» (pp. XXI-XXIII) y una «noticia de los escritores de la historia antigua de México» (pp. XXV-XXXVIII). La carta dedicatoria carece de la dimensión de controversia ya que su destinatario, «los ilustrísimos señores de la Universidad de México», no precisa ser persuadido de que América no es ni un mundo inferior ni un mundo degradado. Este «prodestinatario», «destinatario positivo» o «partidario», cuyas calidades se elogian sobremanera, se define como «un receptor que participa de las mismas ideas, que adhiere a los mismos valores y persigue los mismos objetivos que el enunciador» (Verón, 1987, p. 17). La relación que el enunciador establece con el co-enunciador reposa en una «creencia presupuesta» (Verón, 1987, p. 17) que ni siquiera se tiene que explicitar. Sin embargo, la carta sí se construye sobre la base de elementos de persuasión. El enunciador, después de haber expresado su aprecio y estima por los profesores de la Universidad de México, ejerce presión en este grupo de la élite criolla para que ellos presten la debida 
atención al estudio del patrimonio prehispánico en la Nueva España y opten por una política más activa y eficaz para conservar y explorar los restos de la cultura prehispánica.

Aunque el enunciador comparte con el destinatario de la carta -sus «compatriotas» (pp. XXI-XXIII)- la patria, raras veces usa el «nosotros» (salvo en algunas pocas ocasiones) sino que suele dirigirse a un «vosotros». La separación de la entidad enunciadora del prodestinatario se relaciona estrechamente con la puesta en escena del lugar (lejos del objeto de estudio) desde el que habla el enunciador y el lugar (cerca del mismo objeto) en el que se encuentra el público lector. La carta nos ofrece una escena espacial caracterizada por la ruptura; el lugar de la enunciación se define como un espacio lejos de la tierra que solía compartir con el prodestinatario, más concretamente, «a más de dos mil y trescientas leguas de su patria» (1971, p. XVII). Pero a pesar de «la agobiante distancia del exilio» (Arita, 2000, p. 25) que le separa de su objeto de estudio y a pesar de las dificultades que este alejamiento implica, el enunciador subraya el esfuerzo que hace por la conservación de la herencia histórica de su patria: para ello sirve precisamente el volumen sobre el México Antiguo que ofrece y dedica a sus «compatriotas» (1971, p. XVIII).

Si la carta proemio problematiza la situación de la memoria y del conocimiento de la historia del México Antiguo en la tierra novohispana, el territorio que le causa preocupación al enunciador en el prólogo es el europeo. Ya en el primer párrafo, el enunciador a la vez introduce y ataca los responsables de estas alegaciones falsas, que describe como una «turba increíble de escritores modernos» (1971, p. XXI). Este grupo de «europeos que han escrito sobre América», colectivo responsable de haber ofuscado «la verdad» (1971, p. XXI) acerca del Nuevo Mundo se caracteriza por la tendencia a mentir y a hermosear su trabajo "con hechos inventados por el capricho» (1971, p. XXII). ${ }^{4}$ Al tiempo que destruye el trabajo del adversario por ser mentiroso, el enunciador se construye a sí mismo como su polo opuesto al presentarse como un historiador fidedigno, «enemigo de todo engaño, mentira y afectación» (Clavijero, 1971, p. XXII) cuyo trabajo sólido se basa en múltiples lecturas, buscas de documentación, experiencias y vivencias en y sobre el territorio novohispano. El lazo entre el enunciador y este adversario o contradestinatario reposa, según Verón, precisamente en «una inversión de la creencia: lo que es verdadero para el enunciador es falso para el contradestinatario e inversamente» (1987, p. 18).

El paradestinatario apenas se esboza vagamente en este prólogo que coloca la adversidad en el centro de la escena discursiva: esta figura se suele señalar por medio de términos neutros tales como «lectores» o «muchos». Este público amplio se caracteriza como europeo (Clavijero, 1971, p. XXIII) y, como estos lectores europeos no están familiarizados con la realidad del Antiguo México, la instancia enunciadora destaca que no están acostumbrados al sonido de determinados nombres usados por los antiguos mexicanos, necesitan mapas para entender la geografía antigua del territorio descrito y láminas para tener una idea de los vestidos, edificios, flores y animales de aquella tierra. Este paradestinatario, que ocupa el rol de «tercero» (Goffmann, 1981, p. 141), completa la escena del discurso adversativo al proporcionar una figura cuya posición todavía no se ha determinado y a quien van dirigidos los argumentos del discurso. Sin embargo, en esta fase anticipatoria, el enunciador todavía no desarrolla estrategias de persuasión sino que solo gana la confianza de su destinatario. ${ }^{5}$

Dicha situación cambia en el componente textual siguiente - «Noticia de los escritores de la Historia Antigua de México»-, que ofrece un discurso más argumentativo. Desde la perspectiva de la puesta en escena del debate, este escrito -anejo del prólogo que cierra el aparato paratextual-, agrega más enunciadores y participantes en la disputa. El anejo del prólogo presenta una polifonía de voces -historiadores indígenas y europeos del Antiguo México de los siglos XVI, XVII y XVIII- cuyo aporte a la cuestión de debate es evaluado de manera crítica por la instancia enunciadora. La idea de polémica está muy presente en dicho escrito, a pesar de que el enunciador presenta la lista de historiadores del Antiguo México como un documento cuyo único objetivo sería el de honrar y rescatar del olvido los trabajos de los historiadores americanos «desconocidos en Europa» (Clavijero, 1971, p. XXIII). Aunque el enunciador incluye efectivamente en el anejo fuentes indígenas de información sobre el antiguo México $^{6}$, es sobre todo la actitud crítica del enunciador frente a los estudios publicados

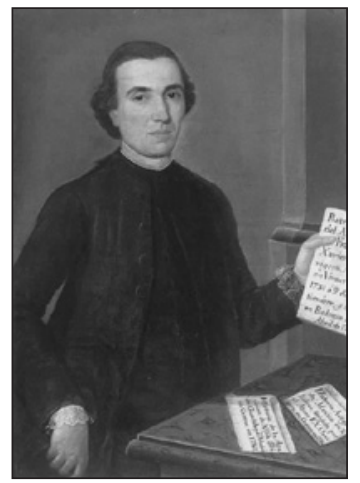

Retrato de Francisco Javier Clavijero

4

García Negroni (1988, pp. 9394) distingue -en esta categoría que Verón denomina "contradestinatario»- entre el "destinatario encubierto», que aparece bajo la tercera persona plural o singular, y el "destinatario indirecto», que se evoca de manera menos explícita, por ejemplo a través de marcas de la negación. En este prólogo, se halla un contradestinatario encubierto, señalado por la tercera persona singular.

5

Esto es, no recurre a estrategias argumentativas otras que la presentación destructiva del contradestinatario y la creación de una imagen fidedigna del enunciador.

6

Esta inclusión, ya de por sí, pone en escena un componente del debate, ya que los estudiosos europeos del Siglo de Oro, tales como De Pauw, rechazaron las fuentes indígenas de información sobre el Antiguo México $y$, aunque pretendieron basarse únicamente en «hechos» (Cañizares-Esguerra, 2001, pp. 45, 51-53), no habían viajado a la tierra novohispana para conocer la naturaleza americana de manera directa sino que sus estudios se fundaban en los relatos de viajeros europeos.

\footnotetext{
La construcción del enunciador en una dinámica de debate: Historia Antigua de México (1780-81) de Francisco Clavijero

EUGENIA HOUVENAGHEL
} 
La pregunta de saber si los escritores europeos del siglo XVIII que han escrito sobre el Antiguo México han estado en la Nueva España es decisiva para Claviiero a la hora de decidir sobre la fiabilidad y el aporte de aquellos trabajos. Sobre la base de este principio espacial, y el trato directo con la gente que este principio implica, Clavijero evalúa positivamente las contribuciones de los italianos Gemelli y Boturini (Clavijero, 1971, p. XXXIII) al conocimiento del México Antiguo.

8

«Descripción del reino de México; su tierra, su clima, sus montes, sus ríos y lagos; sus minerales, sus plantas, sus animales y sus hombres» (Clavijero, 1971, pp. 1-47).

9

El enunciador relata que son otros quienes le han convencido de redactar e integrarlo.

10

Según expone la instancia enunciadora, el libro I no tiene como primer objetivo ofrecer un aporte general acerca del estudio de «las cosas naturales de México» (Clavijero, 1971, p. XXII) sino que se dedica más bien a proporcionar información relacionada con la historia antigua de México y concretamente con «el uso que de ellas [las cosas naturales] hacían los antiguos mexicanos» (1971, p. XXII).

11

El adversario del enunciador adquiere en algunas ocasiones una presencia velada bajo la forma que García Negroni (1988, pp. 93-94) llama "destinatario indirecto", aquel subtipo del contradestintario que se evoca de manera implícita. Así, la instancia enunciadora insiste en que es posible transportar las plantas y los animales de Europa a América sin que degeneren (Clavijero, 1971, p. 31) sino que las semillas, plantas o animales más bien, "se han logrado tan bien como en su propio país» (1971, p. 12), crecen "perfectamente» (1971, p. 15) o se multiplican «con gran felicidad» (1971, p. 41). Así contradice, de manera indirecta, el parecer de Cornelius De Pauw según el que la degeneración es propia de la tierra americana. Este parecer se trata más adelante, en las «Disertaciones», de manera explícita: «se-

\footnotetext{
La construcción del enunciador en una dinámica de debate: Historia Antigua de México (1780-81) de Francisco Clavijero

EUGENIA HOUVENAGHEL
}

por europeos sobre América lo que llama la atención. Además, el enunciador refina la presentación del contradestinatario, que deja de ser un colectivo negativo: se especifican en este discurso nombres de naturalistas e historiadores europeos tales como De Pauw, Buffon, Marmontel, Gage, Raynal y Robertson (Clavijero, 1971, pp. XXXIII-XXV). El enunciador se extiende largamente sobre los errores cometidos en los estudios de aquellos autores europeos -errores «de los cuales se podrían componer gruesos volúmenes» (1971, p. XXXIV)- y denuncia sus «mentiras groseras» $\left(1971\right.$, p. XXXV) ${ }^{7}$. Entre las estrategias de persuasión de que el contradestinatario no puede ser una fuente fidedigna de información, se cuentan no solo argumentos lógicos (que se recitan de forma sistemática y se ordenan) sino también recursos estilísticos (la exageración, preguntas retóricas) y emotivos (el humor, la ridiculización del contradestinatario). La construcción de la argumentación va in crescendo hasta rematar en el siguiente clímax: «En la grande obra titulada La galerie agréable du monde se representan los embajadores mandados antiguamente a la corte de México montados sobre elefantes. Esto es mentir en grande.» (1971, p. XXXV). Tras esta oración, el enunciador cierra los textos anticipatorios e inicia el discurso central, cuyo objetivo principal es informarle mejor al lector sobre el antiguo México y corregir los «errores, despropósitos y mentiras» (1971, p. XXXIV) de los escritores europeos, mentiras a veces tan erradas que provocan la risa, como el ejemplo de los elefantes ilustra de manera concluyente.

\subsection{El primer libro}

El primer libro 8 de la Historia Antigua de México no se presenta como un apartado centrado en la polémica cultural acerca de la supuesta inferioridad del Nuevo Mundo, ni mucho menos. En el prólogo, la instancia enunciadora explica que no le parece imprescindible la inclusión de este libro -que «muchos calificarán de importuno» (Clavijero, 1971, p. XXII) mientras que otros lo

gún Paw», dice el enunciador, «todos los propios de América son más pequeños, más deformes y más débiles, [...] y los que se trasladaron a ella de otra parte, inmediatamente degeneraron, así como todas las plantas de Europa transplantadas a América» (Clavijero, 1971 , p. 422).

considerarán «compendioso y superficial» (1971, p. XXII)- en el volumen'. El contrato comunicativo establecido con el lector acerca de este libro gira en torno a los límites de la información, relacionada con la naturaleza americana, que este componente pretende transmitir ${ }^{10}$. A primera vista, la controversia efectivamente no ocupa una posición relevante en este escrito. La instancia enunciadora bien evita temas polémicos, bien anuncia su intención de «refutar» más adelante, en las «Disertaciones», algún que otro «error nacido de ignorancia» y difundido por los europeos (1971, pp. 31, 41)11. Por lo general, es un apartado predominado por la descripción minuciosa y viva-, no por la argumentación.

Sin embargo, hay un componente del primer libro que, a pesar de los propósitos descriptivos del enunciador, sí se orienta hacia la polémica, a saber, el aparato de notas que se ubica a pie de página. El hecho de que allí aparezca la idea de debate tiene que ver con la misma temática tratada -el mundo natural americano es el eje central de la «Disputa del Nuevo Mundo»12- y con la puesta en escena de otros participantes en el debate en las anotaciones. La entidad enunciadora cita o se refiere a pasajes relevantes de la obra de historiadores y cronistas ${ }^{13}$ y los comenta, revelando que el escritor en cuestión se ha equivocado, se ha informado mal o ha malinterpretado un texto. El enunciador explica, a continuación, por qué aquel discurso ajeno, que pretende ser cierto, es «un engaño» (n. 2, n. 44, n. 50, n. 60), «un error» (n. 9), «falso» (n. 5), «arbitrario» (n. 5), «un despropósito» (n. 17), «una confusión» (n.29) o «una mentira» (n. 30). El enunciador propone, a continuación, de manera lógica y clara, su visión de los fenómenos en cuestión y para ello, se basa en una amplia documentación, en su propia experiencia o en el testimonio fidedigno de los habitantes actuales de la región. Al hacerlo, construye su propio perfil de científico crítico, racional, bien informado y en busca de la verdad. En aquellas notas a pie de página, a pesar de que se ubican en el margen del texto, se lleva a cabo una parte de la construcción de la figura del enunciador que no carece de importancia.

12

Si comparamos con la polé mica Sepúlveda-Las Casas del siglo XVI, centrada en el indio, con el debate europeo-ameri- cano del siglo XVIII, se nota que se ha mudado el interés del habitante del mundo americano al mundo natural americano y a su propia naturaleza. 
En el cuerpo del texto, en el cual el enunciador, tal como había anunciado en el prólogo, se dedica a describir la naturaleza y el uso que los antiguos mexicanos hacían de ella, se construye una dimensión diferente de la identidad del enunciador. Las actividades emprendidas por el enunciador ya no son de carácter racional sino que se trata de experiencias y observaciones, cuya dimensión sensitiva ${ }^{14}$ predomina el discurso. En muchas ocasiones, se agrega también el enfoque emotivo y/o estético ${ }^{15}$ del enunciador sobre los fenómenos naturales delineados. Como consecuencia, las descripciones de la naturaleza novohispana distan de ser científicas y frías. El enunciador se perfila ya no como un historiador crítico y racional, sino como una persona humana observadora y sensitiva. La instancia enunciadora opta, en el cuerpo del texto, por el «yo» de la primera persona singular para referir a las actividades de observación y para describir las sensaciones producidas en los sentidos por los fenómenos de la naturaleza novohispana. Sitúa aquellas experiencias, además, en un momento muy cercano al «ahora» de la enunciación. Este efecto se produce gracias al tiempo verbal: el «yo»-enunciador describe las plantas y animales de la tierra novohispana usando el pretérito perfecto compuesto ${ }^{16}$. El tiempo pretérito perfecto compuesto provoca el efecto de conectar dichas actividades con el acto de enunciar; aproxima, además, el tiempo y espacio de las observaciones y experiencias al "aquí» y «ahora» de la enunciación ${ }^{17}$. En fin, la entidad enunciadora recurre en este primer libro a procedimientos de temporalidad y adjetivación para ubicarse en una zona de contacto directo con el objeto de estudio. En este apartado descriptivo, la relación intensa y directa del «yo» con la realidad espacial es la piedra de toque de la construcción de la figura enunciadora.

13

Escriotres tan diversos tales como Boturini, Torquemada, Hernández, Burgoa, Cortés, el conquistador anónimo, Gomara, Sahagún, Bernal Díaz, Acosta, Herrera, Solís, Betancourt, Motolinia, Buffon.

14

Las cosas naturales se describen, por ejemplo, como "gustosas» (Clavijero, 1971, p. 12) "recomendables por su suavísimo y delicado olor» (1971, p. 11), «tiernas» $(1971$, p. 11$)$

El lector al que se dirige la instancia enunciadora no se construye en detalle en este texto ni adquiere mucha presencia explícita: está claro que el destinatario es de Europa y se caracteriza por el desconocimiento de la naturaleza novohispana. Sin embargo, las descripciones de los fenómenos son tan claras, directas, detalladas y orientadas hacia las sensaciones de los sentidos, que parecen ser concebidas para producir en el lector el efecto de participar, a través del texto, en la experiencia sensorial de la naturaleza novohispana. El enunciador desarrolla también su visión sobre la naturaleza americana desde un punto de vista comprensible para el lector europeo: imagina en el texto las posibles reacciones del lector europeo al verse confrontado con los elementos de la naturaleza novohispana, relata que una determinada especie se ha llevado a Europa, compara la naturaleza de la Nueva España con fenómenos parecidos que existen en el espacio europeo ${ }^{18}$, coteja el uso que hacían los antiguos mexicanos de una determinada planta con el provecho que sacan los españoles de la misma, compara una determinada especie de Europa con la misma especie en América, menciona sistemáticamente el término de los antiguos mexicanos al lado del nombre dado posteriormente por los españoles al mismo fenómeno natural, etc. En total, se puede decir que la mirada del enunciador sobre el objeto de estudio no es exclusivamente americana ${ }^{19}$ sino que es tanto europea como americana $y$ ofrece al destinatario europeo numerosos componentes reconocibles; en el discurso se crea, así, una dinámica comunicativa que ofrece a dicho lector varios puntos de anclaje que le permitan conectar con el mundo descrito.

«admirables» (1971, p. 29) «felices» (1971, p. 8), "alegres» (1971, p. 10). Sobre la dimensión estética en Historia Antigua de México, véase también Arvizu Valencia (2010).

\section{6}

Algunos ejemplos: "he visto» (Clavijero, 1971, p. 47), «he numerado» (1971, p. 41), "he visto pagar por uno de ellos» (1971, p. 31), "he conocido» (1971, pp. 45-46). El enunciador menciona también los animales o plantas que no ha visto o de características que no puede confirmar, testimonio que produce el mismo efecto de ubicar al enunciador en el aquí y ahora de la Nueva España y, además, subraya la sinceridad del enunciador a la hora de referirse a sus propias observaciones. «Este cuadrúpedo es también comunísimo; pero no me acuerdo de haberlo visto en los lugares en que se crían las ardillas de tierra» (Clavijero, 1971, p. 26); "no he tenido noticia de algún caso particular que confirme este común creencia [de que es venenosa esta araña] (1971, p. 41).

17

El pretérito indefinido e imperfecto se reservan para referir al uso que solían hacer los antiguos mexicanos o españoles en aquella época antes de la conquista o directamente después de la conquista, a los elementos descritos de la naturaleza. El enunciador habla, por ejemplo, de un pájaro "al que llamaron comendador los antiguos españoles» (Claviijero, 1971, p. 32) o refiere que "los mexicanos la [la lagartija] dividían en dos clases» (1971, p. 33) o menciona que «los antiguos mexicanos no comían solamente los huevos [de la mosca] sino aun las mismas moscas hechas masa y cocidas con nitro» (1971, p. 40). Sólo cuando el enunciador incluye el año de la observación o de la experiencia, que es de carácter más bien excepcional, suele recurrir al pretérito indefinido para expresar las experiencias de «yo» (1971, p. 41).

En otras ocasiones y especialmente cuando se refiere a sus viajes por el territorio o a un determinado año, usa el pretérito perfecto e imperfecto, por ejemplo cuando describe el pájaro madrugador tzacua: «En las veces que viajé por el reino Muchuacán, en donde más abundan, me servían de despertador para levantarme y apresurar mi partida.» (1971, p. 32)

18

Algunos ejemplos: «La [avispa] que llaman los mexicanos quetzalmiahuatl, es semejante en todo a las comunes de Europa» (Clavijero, 1971, p. 40); "entre las especies de mosquitos, los zancudos, que son tan comu nes en Europa y especialmente en Italia» (1971, p. 40), "están libres de muchas enfermedades que son frecuentes en los españoles (1971, p. 45); "la misma inmovilidad y entorpecimiento se sobserva en Europa en los lirones» $(1971$, p. 30$)$.

19

La instancia enunciadora parece situarse, por lo tanto, en este lugar paratópico entre dos mundos, tal como ya ha apuntado Nordenflycht (2010), en la intersección paratópica de dos categorías espaciales.

\footnotetext{
La construcción del enunciador en una dinámica de debate: Historia Antigua de México (1780-81) de Francisco Clavijero
}

EUGENIA HOUVENAGHEL 

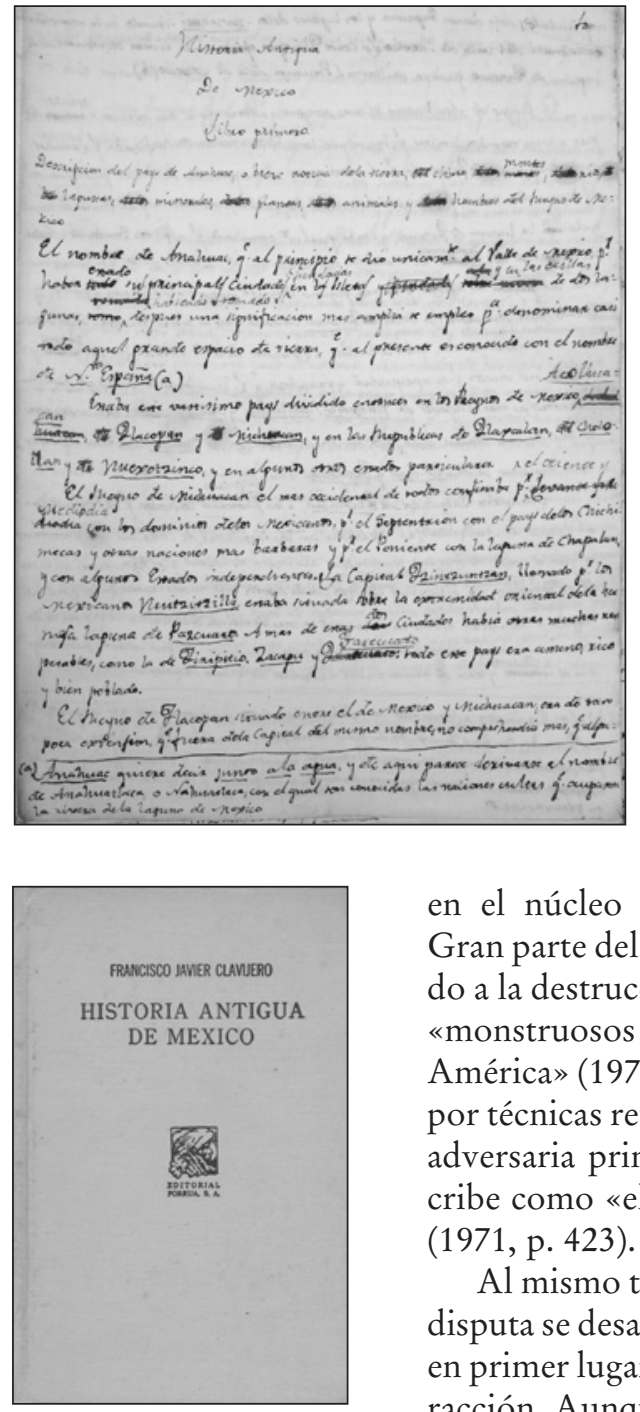

20

Las «Disertaciones» han sido agregadas, concretamente, para «ilustrar» el discurso principal, esto es, para "confirmar la verdad» (1971, p. 422) del mismo.

21

Como explica el enunciador, la obra de Cornelius De Pauw es «una sentina ○ albañal», que "ha recogido todas las inmundicias, esto es, los errores de todos los demás) (Clavijero, 1971, p. 422). A esta obra se agrega más adelante, la del conde de Buffon (1971, p. 423).

La construcción del enunciador en una dinámica de debate: Historia Antigua de México (1780-81) de Francisco Clavijero

EUGENIA HOUVENAGHEL (1971, p. 423).

\section{I.3. Las Disertaciones}

Después de los 10 libros que contienen la Historia Antigua de México propiamente dicha, aparece otro componente del paratexto que se titula «Al lector» y que sirve de antesala a la última parte del volumen, las «Disertaciones». El texto anticipatorio establece un nuevo tipo de contrato con el lector: la instancia enunciadora presenta las «Disertaciones» como un complemento «necesario» (Clavijero, 1971, p. 422) ${ }^{20}$ de la Historia Antigua de Méxi$\mathrm{co}$, se propone refutar en ellas los errores del contradestinatario y coloca, así, el debate en el núcleo de esta sección del volumen. Gran parte del escrito anticipatorio va dedicado a la destrucción de las Investigaciones, este «monstruosos retrato que de Paw hace de la América» (1971, p. 423) y al ataque, reforzado por técnicas retóricas de exageración, la figura adversaria principal ${ }^{21}$ que el enunciador describe como «el principal blanco de sus tiros»

Al mismo tiempo, la puesta en escena de la disputa se desarrolla y se complica; se agregan, en primer lugar, nuevos participantes a la interacción. Aunque la instancia enunciadora parece situarse, a primera vista, en una posición diametralmente opuesta al contradestintario, la situación cambia cuando se introduce en el espacio representativo del debate otro participante más radical todavía que se coloca, de verdad, en el otro extremo del espectro. A las alegaciones acerca de la inferioridad del Nuevo Mundo emitidas por el adversario se oponen diametralmente los elogios excesivos del Nuevo Mundo y la defensa de la superioridad de América sobre el Mundo Antiguo (Clavijero, 1971, p. 423). El enunciador, por su parte, rechaza ambas posiciones como reprobables, «ya que el alabar apasionadamente el propio país sobre los demás parece más de niños que se pelean que de hombres que discuten» (1971, p. 423), y afirma no encontrarse ni en uno ni en otro extremo; como consecuencia, consigue ubicarse a sí mismo en una posición aparentemente equilibrada y sensata, en el punto medio equidistante de ambos extremos despreciables por falta de imparcialidad. Se agrega, pues, una voz más a la discusión en este prólogo, procedimiento cuyo objetivo no parece hallarse en el refinamiento de la representación de un debate complejo, sino en la presentación más matizada y ventajosa de la posición que la figura enunciadora ocupa en este mismo espacio de debate.

La temática de las disertaciones es elegida en función de la controversia: cada disertación gira en torno a un aspecto sobre el que existe polémica y se construye como refutación de enunciados anteriores, considerados como falsos o mentirosos, acerca del tema en cuestión. La estructura de las secciones también es abiertamente argumentativa: el mismo esquema estructural concebido en función de la persuasión del paradestinatario se repite en cada disertación y se desarrolla sobre todo en dos lugares estratégicos, al inicio y al final de la disertación, que toman la forma de una introducción y una conclusión. Para empezar, la instancia enunciadora presenta la dificultad del tema-que radica en la existencia de confusión o discordancia acerca de un determinado aspecto del Antiguo México-, explica su propósito de «averiguar lo cierto» (1971, p. 443) acerca del tema y comenta la metodología meticulosa a la que recurrirá para cumplir con lo prometido. La mini-conclusión de cada disertación es el lugar idóneo para hacer el balance acerca de la utilidad del ejercicio realizado en cada una de las disertaciones; en ella el enunciador suele confirmar que ha «aclarado [...] muchos errores» (1971, p. 524).

El enunciador construye, igual que en las partes argumentativas analizadas anteriormente, una imagen de sí mismo que se basa en la destrucción de la figura del adversario. El paradestinatario, por otra parte, se construye de manera paralela a la figura enunciadora. En esta dinámica, el paradestinatario y el enunciador se aproximan y se delinean como un colectivo de identificación que deja aislada a la figura adversaria. Así es que se crea un «nosotros inclusivo» formado por dos participantes en la argumentación, participantes que se entienden y hablan el mismo lenguaje para formar un colectivo del que se excluye el contradestinatario. Los rasgos a base de la construcción de esta alianza entre la figura destinataria y la figura enunciadora son principalmente tres: la capacidad lógica, la objetividad y el cristianismo. Los lectores a quienes se dirige la argumentación se caracterizan por 
«escuchar la razón» (1971, p. 516), por ser «imparciales» (1971, p. 506) y por «respetar la ley divina» (1971, p. 442). Es de notar, en este contexto, la gran estima que evoca la figura enunciadora por el paradestinatario que está dispuesto a profundizar en cuestiones de debate acerca del Nuevo Mundo, está familiarizado con las obras más difundidas en $\mathrm{Eu}-$ ropa sobre América y dispone de un amplio bagaje intelectual general. ${ }^{22} \mathrm{La}$ construcción de la figura sabia y capaz del paradestinatario contrasta vivamente con la imagen de ignorancia y falsedad que se crea, de una manera salpicada con ironía, del contradestinatario -figura que aparece acompañada por marcas de desautorización y descalificación-. Destacan particularmente las estrategias de lo que la retórica denomina argumentación «sobre la persona» o ad hominem, como ya destacó Villoro (1950, p. 99), es decir, contra-argumentos no centrados sobre el enunciado del otro sino sobre la persona que emite el enunciado. Al aislamiento de la figura de Pauw (y, en menor medida, de Buffon) contribuye también la puesta en escena de una multitud de voces prestigiosas y la evocación de sus respectivos discursos, tan dignos de crédito, que contradicen las ideas del adversario. Un gran número de voces desacredita, a coro, la visión del adversario; se acentúa, así, la posición aislada del contradestinatario.

El uso de los verbos atribuidos a los diferentes participantes en la polémica es crucial para construir discursivamente un simulacro de las actividades realizadas en la disputa. Al contradestintatario, figura a la que se concede un lugar preponderante en el escenario, se atribuyen, en primer lugar, actividades verbales de agresión y de maliciosidad («vilipendiar» (1971, p. 506); «envilecer» (1971, pp. 506, 523, 512) «disimular» (1971, p. 506), «callar maliciosamente» (1971, p. 519), «injuriar» (1971, p. 522), «echar en cara» (1971, p. 522), «infamar» (1971, p. 522) y actividades que demuestran una falta de rigor en su aproximación a la documentación disponible («ignorar» (1971, p. 519), «no admitir el testimonio» (1971, p. 513$)$, «suponer» (1971, p. 503), «olvidar» (1971, p. 506), «rehusar la declaración» (1971, p. 513), «ser mal informado» (1971, p. 518). Después, se marca la presencia de la figura del enunciador por referencias a actividades intelectuales que reflejan su autoridad en la materia («estar seguro» (1971, p. 447), «estar cierto» (1971, p. 504), «saber» (1971, p. 447, «no dudar» (1971, p. 512), «asegurar» (1971, p. 547), «estar persuadido» (1971, p. 504), «testificar» (1971, p. 522) y su eficacia a la hora de convencer («persuadir» (1971, p. 445), «demostrar» (1971, p. 537)). Finalmente, el receptor de aquellas actividades de persuasión, exitosas en el caso del enunciador y vanas en el caso del paradestinatario, se pone en escena como una figura que reacciona frente a los dos puntos de vista expuestos anteriormente. Se le atribuyen o bien actividades de recepción intelectual crítica («poner en duda» (1971, p. 502), «no creer» (1971, p. 449), «no fiarse de» (1971, p. 518), «decidir» (1971, p. 506) o bien actividades de recepción intelectual positiva («creer» (1971, p. 448), «aceptar» (1971, p. 506), «dar fe» (1971, p. 522), «fiarse», (1971, p. 481), «entender», (1971, p. 477), «ver» (1971, p. 504), «persuadirse» (1971, p. 524)). Se distingue, pues, en la puesta en escena, entre la reacción que se espera del lector frente a los argumentos manejados por el enunciador, por una parte, y su reacción frente a la argumentación realizada por el contradestinatario, por otra. Así, en estas tres fases (enunciado del contradestinatario, defensa del enunciador, reacción del lector) se representa discursivamente la dinámica de la interacción entre los tres participantes principales en un simulacro de la disputa, como si fuera una pieza de teatro.

\section{Reflexiones finales}

El camino que hemos escogido en nuestra aproximación a la Historia Antigua de México fue fijado por dos consideraciones generales. La primera de ellas obedece a la manera cómo este texto se inserta en la «Disputa del Nuevo Mundo» y se construye como un discurso adversativo. Por otra parte, la reflexión sobre la manera en la que el texto pone en escena y desarrolla el debate, constituye la segunda perspectiva de nuestra lectura del discurso de Clavijero. Según nuestra hipótesis, la representación en el mismo texto de la dinámica de la discusión dieciochesca que confronta ilustrados europeos y criollos nos ofrece pistas para comprender mejor el proceso de construcción de la identidad del propio enunciador.

Ahora bien, resulta que los apartados en los que la controversia adquiere mayor presencia no se ubican en el texto principal de la Historia Antigua de México, sino que se
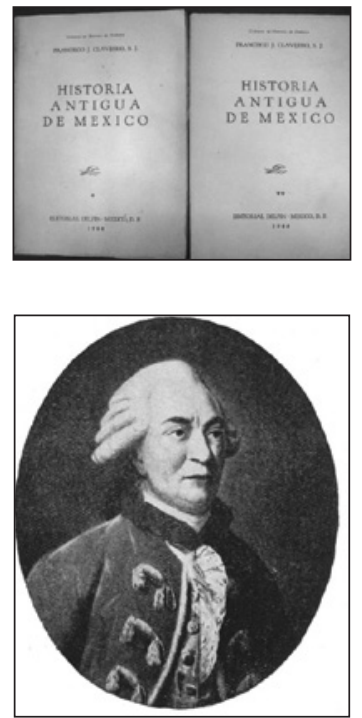

Grabado conde de Buffon, de P. M. Alix

22

Se exige más del destinatario en estas disertaciones que en el primer Libro. El enunciador ex plica que tratar estos asuntos en la Historia sería aburrido, difícil, y llegaría a «interrumpir el hilo de la narración con disputas espinosas》 (Clavijero, 1971, p. 443), introducir notas "extremamente largas» (1971, p. 443). El enunciador avisa también que los apartados que siguen en las disertaciones, "son enfados para los que no tienen interés en la ilustración de estos puntos de cronología» (1971, p. 443) Se exige más de él ya que las cuestiones tratadas giran en torno a puntos polémicos y exigen un tratamiento más detallado y elaborado.

La construcción del enunciador en una dinámica de debate: Historia Antigua de México (1780-81) de Francisco Clavijero

EUGENIA HOUVENAGHEL 


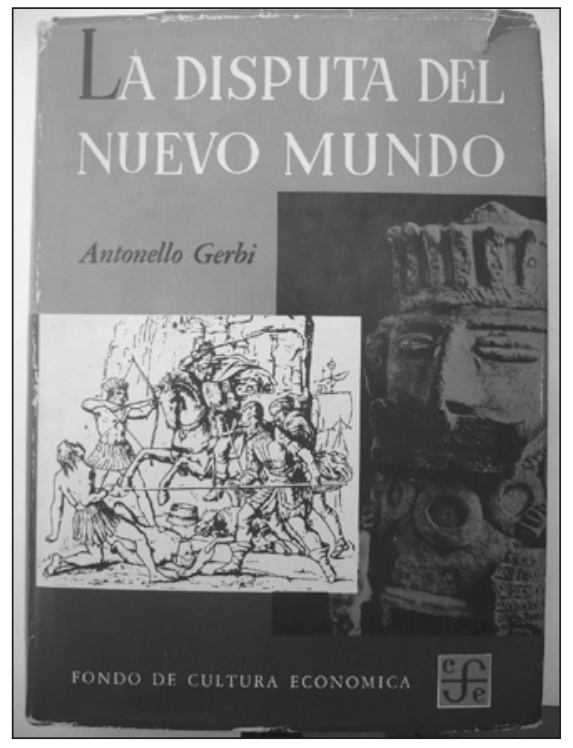

colocan fuera, en el margen o en zonas periféricas. Entre dichos apartados en los cuales se concede un lugar relevante al debate, contamos la «Noticia de los escritores de la historia antigua de México»-que se sitúa en posición de anejo frente al aparato textual-, las notas a pie de página del primer libro y las «Disertaciones»-las cuales se presentan como complemento del cuerpo del texto-. Como lo anuncia el título, se privilegian en la organización estructural del texto aquellas subdivisiones dedicadas a proporcionar información acerca de la historia del Antiguo México sobre los apartados concebidos para contradecir enunciados falsos acerca del Nuevo Mundo, que se colocan en partes marginales del texto. Estas subdivisiones que ponen en escena la dimensión de la polémica son, lógicamente, de índole más argumentativa que el cuerpo del texto, de carácter principalmente descriptivo.

A pesar de esta ubicación «fuera» o «al servicio» del texto principal, aquellas secciones argumentativas contribuyen a esbozar un fragmento relevante de la identidad del enunciador. La edificación de la instancia enunciadora se realiza por medio de la puesta en escena de la controversia, más concretamente, a través del establecimiento de relaciones dinámicas entre el enunciador y uno o varios participantes en el debate. En primer lugar, la construcción de la figura de la instancia enunciadora se apoya en la destrucción discursiva de la figura del adversario; ambas funciones (construcción y destrucción) se entrelazan tan estrechamente que son indisociables en el texto. En segundo lugar, el enunciador se edifica a base de una serie de características y capacidades que comparte con el paradestinatario y que les distingue del adversario. En tercer lugar, la identidad del yo-enunciador toma forma a través del simulacro de las acciones sucesivas de los participantes en el debate: la puesta en escena de la discusión apoya y refuerza la hipótesis según la que los «naturalistas de gabinete» europeos se equivocan mientras que el enunciador sí dispone de argumentos válidos para persuadir al lector.

Rasgos relacionados con la moral -como la sinceridad y la integridad-, con la acti- tud científica -tales como la racionalidad, la objetividad y el espíritu crítico- y con una determinada espiritualidad -la adhesión al cristianismo- se juntan, en estas subdivisiones de tonalidad más argumentativa, para modelar al enunciador. Se trata de rasgos que no se marcan exclusivamente como americanos, sino que sirven, al contrario, para formar un colectivo de identificación en el que sea posible incluir tanto el paradestinatario europeo, como el enunciador, marcado como "mexicano» (Clavijero, 1971, p. XVII). Rasgos, actitudes $\mathrm{y}$ valores, en fin, que construyen un puente entre los dos continentes y que contradicen, así, la polarización Europa/América que rige la «Disputa del Nuevo Mundo».

La construcción de la instancia enunciadora es diferente en el núcleo del texto cuya esencia es de índole descriptiva. En las partes orientadas a proporcionar datos históricos del Antiguo México, el enunciador se vale de otra categoría que la del destinatario para construir una imagen de sí mismo: establece una relación estrecha (sensitiva y emotiva) con la realidad espacial que constituye el objeto de estudio. A través de la descripción del espacio, con su naturaleza y sus gentes, se actualiza el contacto directo del «yo»-enunciador con la tierra novohispana; la descripción produce, a la vez, el efecto de aproximar el lector, marcado como europeo, a la realidad referida. De nuevo, el enunciador recurre a estrategias discursivas que tienen el efecto de tender un puente entre Europa y América.

Las dos maneras de edificar una identidad del enunciador, -la primera basada en la dimensión del co-enunciador y la segunda en la categoría espacial- se complementan y se fundan en una imagen siempre doble y dialógica. Estamos frente a la creación de una escena de enunciación híbrida en la que participan principalmente dos modalidades: la descriptiva, -en la que experiencias sensitivas y estéticas del «yo» predominan- y la argumentativa, -en la que actividades racionales e intelectuales del «yo» toman el relevo-. La voz del enunciador es la de un sujeto que, moviéndose entre dos modalidades textuales, pone en escena y hace interaccionar entre sí dos diferentes «fragmentos de identidad». Los fragmentos identitarios tienen un mecanismo de acción en común: borrar fronteras entre el lector europeo y el enunciador «mexicano» (Clavijero, 1971, p XVII). Más allá del espíritu de debate que opone euro- 
peos a criollos, la instancia enunciadora se presenta como una figura que subraya aquellos elementos que Europa y América tienen en común e invita los europeos, sobre esta base, a acercarse a la realidad americana para verla con nuevos ojos.

\section{Bibliografía}

Arita, Héctor (2001), «Las tres hipótesis macroecológicas de Francisco Javier Clavijero», Ciencias 60-61, Octubre 2000-Marzo 2001, pp. 25-27.

Arvizu Valencia, J. Antonio (2004), «Supuestos y complejidad para una estética en la Historia Antigua de México de FJC», Pensamiento Novohispano 5, 2004, pp. 107-119.

Brading, David (1991), The First America: The Spanish Monarchy, Creole Patriots, and the Liberal State 1492-1867, Cambridge, Cambridge University Press.

Cañizares-Esguera, Jorge (2001), How to write the History of the New World: Historiographies, Epistemologies and Identies in the Eighteenth-Century Atlantic, Stanford, Stanford University Press.

Charaudeau, Patrick y Dominique Maingueneau, (eds) (2005), Diccionario de análisis del discurso, Buenos Aires, Amorrortu.

Clavijero, Francisco (1971), Historia Antigua de México, México, Porrúa.

Empaire, Arleny León d» (1993), Felipe Salvador Gilij: Nuevas perspectivas americanas en la crónica dieciochesca, Caracas, Universidad Católica Andrés Bello.

García Negroni, María Marta (1988), La destinación en el discurso politico: una categoría múltiple, en Lenguaje en Contexto I (1/2), pp. 85-111.

Gerbi, Antonello (1993), La disputa del Nuevo Mundo: Historia de una Polémica, trad. de Antonio Alatorre, México, Fondo de Cultura Económica.

Goffmann, E. (1981), Façons de parler, Paris, Minuit.

Hernández Sotelo, Anel (2002), «Francisco Javier Clavijero: una revisión historiográfica», Boletin Cultural de la ENAH, Octubre de 2002, pp. 22-27.

Kohut, Karl (2008), "Clavijero y las disputas sobre el Nuevo Mundo en Europa y América», Destiempos.com, México Marzo-Abril 2008, Año 3, Número 14.

Maingueneau, Dominqiue (1999), «Ethos, scénographie, incorporation. ", Amossy, R., Images de soi dans le discours. La construction de l»éthos, Paris-Lausanne, Delachaux et Nestlé.

Maingueneau, Dominique (1993), Le contexte de l'cuvre littéraire: énonciation, écrivain, société, París, Dunod.

Nordenflycht, Adolfo de (2010), «Paratopía del exilio jesuita americano: Historia natural y narración literaria en Juan Ignacio Molina, Francisco Javier Clavijero y Juan de Velasco», Acta Literaria $\mathrm{N}^{\circ}$ 40, I sem (91-108), 2010.

Perelman, Chaïm (1989), Tratado de la argumentación. La nueva retórica, Madrid, Gredos.

Ronan, Charles E. (1977), Francisco Javier Clavigero, Roma, Institutum Historicum.

Veron, Eliseo (1987), «La palabra adversativa» en $A A V V$ El discurso político. Lenguajes y acontecimientos, Buenos Aires, Hachette, pp. 13-26.

Villoro, Luis (1950), «4. Francisco Javier Clavijero", Los grandes momentos del indigenismo en México, México, El Colegio de México, pp. 95-125.

Fecha de recepción: 15/03/2013

Fecha de aceptación: 29/07/2013
La construcción del enunciador en una dinámica de debate: Historia Antigua de México (1780-81) de Francisco Clavijero

EUGENIA HOUVENAGHEL 